\title{
Knowledge of neonatal danger signs, care seeking practice and associated factors among postpartum mothers at public health facilities in Ambo town, Central Ethiopia
}

\author{
Gizachew Abdissa Bulto ${ }^{1 *} \mathbb{D}$, Daniel Belema Fekene ${ }^{1}$, Berhanu Ejara Moti ${ }^{1}$, Getu Alemu Demissie ${ }^{2}$ \\ and Keneni Berhanu Daka'
}

\begin{abstract}
Objective: Neonatal mortality has remained high in Ethiopia inspite of different efforts being undertaken to reduce this negative trend. Early detection of neonatal illnesses has an important step towards improving newborn survival. Toward this end, there is a need for postpartum mothers to be able to identify signs in neonates that signifies severe neonatal illnesses. There is limited information about the knowledge of post-partum mothers on NDSs and associated factors in the study area. This study aims to assess knowledge of NDSs, care-seeking practice and associated factors among postpartum mothers in Ambo town, Ethiopia, 2018. A systematic random sampling was employed to select respondents and data was collected through face-to-face interviews. Both bivariate and multivariable logistic regressions were utilized.

Results: One-fifth 82 (20.3\%) of postpartum mothers have good knowledge about NDSs. Only $60.5 \%$ of mothers whom their baby developed danger-sign sought medical care for their baby from health facility immediately. Mothers who have diploma/more education ( $A O R=5.25, \mathrm{Cl} 1.48-18.59$ ), whose current baby developed danger-signs $(A O R=3.18 \mathrm{Cl} 1.06-9.52)$, having PNC follow-up $(A O R=2.29, \mathrm{Cl} 1.24-4.24)$ and receiving counseling on newborn care after delivery ( $A O R=1.78, \mathrm{Cl} 1.04-3.04$ ) were factors associated with having good knowledge on NDSs. In this study the level of postpartum mother's knowledge on NDSs and care-seeking practice were low.
\end{abstract}

Keywords: Knowledge, Neonatal danger signs, Health care seeking practice, Ambo town

\section{Introduction}

The first 28 days of life the neonatal period are the most vulnerable time for a child's survival. Globally, 2.6 million newborns died in 2016 or 7000 every day and Sub Saharan Africa accounts 38\% of global newborn deaths. Half of all newborn deaths occurred in: India, Pakistan, Nigeria, Democratic Republic of Congo and Ethiopia. Studies showed that there are disparities across regions and countries to end preventable deaths of newborns to at least as low as 12 deaths per 1000 live births [1-3].

\footnotetext{
*Correspondence: gizachab@yahoo.com

${ }^{1}$ Department of Midwifery, College of Medicine and Health Sciences, Ambo University, Ambo, Ethiopia

Full list of author information is available at the end of the article
}

Majority of neonatal deaths (46.3\%) occur within the first $24 \mathrm{~h}$ and $75 \%$ occur during the 1 st week of life $[4,5]$. In Ethiopia, neonatal-mortality ranges from 27.6 to $63 / 1000$ live-births with 37 in 2011 and 29/1000 live-birth in 2016 [6-10].

Globally preterm birth, intrapartum related complications (birth asphyxia), infections and birth defects cause most neonatal deaths [5]. In Ethiopia neonatal sepsis, birth asphyxia and trauma, prematurity, congenital anomalies and acute respiratory infections were identified as the leading causes of neonatal deaths $[6-8,11,12]$.

Neonates and young infants often present with nonspecific symptoms and signs of severe illness. Neonatal danger sings (NDSs) signify the presence of clinical signs 
that would indicate high-risk of neonatal morbidity and mortality and the need for early therapeutic intervention $[5,13,14]$. In rural eastern Uganda newborns with danger-signs were at higher risk of death than those who weren't [2]. Studies indicated that healthcare-seeking behavior of mothers was affected by their knowledge on NDSs which is important to recognize serious illnesses on the newborns. Maternal knowledge of NDSs and delays in deciding to seek-care were major contributors for neonatal mortality $[15,16]$. From study done in four regions of Ethiopia only a third of women who reported neonatal illness had sought care [16]. In Tenta districts, only $41.3 \%$ of mothers sought medical care for neonatal danger signs [16].

Knowledge of mothers on NDSs varies in different studies; in Nepal Mean knowledge of $26.30 \%$, Kenya $84.5 \%$ of mothers attending well-baby clinic had low level of knowledge, and in Ethiopia 50.6\% in Mekelle city, 31.3\% in Wolkite town, 43.7 in Aksum town, 50.3\% in Chencha district, $18.2 \%$ in Gondar town and $21.7 \%$ in Woldia Hospital [17-23]. Studies indicated that different factors were affecting mother's knowledge on NDSs. Lack of specificity of the clinical manifestations of various neonatal illnesses and delay in seeking care were resulting in huge mortality [17-19, 21, 24, 25].

In Ethiopia knowledge on NDSs were diverse, neonatal mortality rate is unacceptably high with little reduction; it is important to develop appropriate strategies and to reduce these unacceptably high death rates. Even though post-natal care (PNC) is one of the most important interventions for reduction of maternal and neonatal mortality it is not provided in a holistic manner including all PNC packages. The knowledge of postpartum mothers about NDSs, care-seeking practices for their newborn with danger-sign and associated factors in Ethiopia are limited, and there is no study done in the study area. Therefore the aim of this study is to assess knowledge on NDSs, care-seeking practice and associated factors among postpartum mothers in Ambo town.

\section{Main text \\ Methods \\ Study design, area and period}

Institutional based-descriptive cross-sectional study was conducted in public health facilities of Ambo town, from February 1st to March 30th 2018 in Ambo town, Oromia region. In Ambo town there are one University hospital, one General Hospital, 2 public health centers, and 13 private clinics. All postpartum mothers who brought their infant to immunization units for the first time at public Health Facilities in Ambo town and who were randomly selected during data collection were our study population. All temporary caregivers who brought infants for immunization were excluded.

\section{Sample size and sampling procedure}

Sample size was calculated using a single population proportion formula by considering: margin of error (5\%), 95\% confidence level $50.6 \%$ proportion of mothers who have good knowledge on NDSs taken from study done in Mekele town [17] and 5\% non-response rate the final sample size becomes 404 .

All three public health facilities providing immunization services were included in the study. Systematic random sampling technique was used to select 404 study subjects by using their immunization registration number as a sampling frame. The number of respondents were proportionally allocated based on their performance report and data was collected every 3rd interval, by using those health facilities 3 months' performance of previous quarter [Ambo general hospital (461), Ambo health center (343) and Awaro health center (247)].

\section{Measurements}

Good knowledge of neonatal danger sign: Mothers who have mentioned three or more from the 11 key danger signs of neonate without prompt $[17,18,20,26]$.

The key neonatal danger signs include: Unable to feed/ poor feeding, convulsion, respiratory rate of $60 /$ more (fast breathing), severe chest in-drawing (difficulty in breathing), temperature of $=37.5{ }^{\circ} \mathrm{C}$ (fever), temperature $=35.5{ }^{\circ} \mathrm{C}$ (hypothermia), only moves when stimulated/not even when stimulated (weakness/lethargy), yellow soles (sign of jaundice), umbilicus redness or draining pus, skin boils, or eyes draining us (sign of local infection) and vomiting [14].

Care-seeking practice for NDSs: Those mothers who have taken their neonates to hospital or health center immediately after the neonate have developed danger signs.

\section{Data collection technique, processing and analysis}

Structured interview-administered Afan-Oromo version questionnaire adapted from reviewing different relevant similar literatures were used to collect data. A pretested questionnaire consisting of socio-demographic, maternal/obstetric health service utilizations, obstetric factors, knowledge of NDSs and care-seeking practices was used. Collected data were checked for completeness, coded and entered into EPI Info version 3.5.4 and exported to SPSS version 20 for analysis. Bivariate analysis was conducted primarily to identify those variables which are found to be associated with knowledge on NDS at $\mathrm{p}$-value of $<0.2$. Multivariable logistic regression analyses were conducted to identify associated factors at $p$-value of $\leq 0.05$. Ethical 
clearance was obtained from ethics review committee of Ambo University, College of Medicine and Health Sciences.

\section{Results \\ Social demographic characteristics and health care utilization among respondents}

A total of 404 mothers were interviewed during data collection making the response rate of $100 \%$. In this study majority $371(92 \%)$ of them were in the age group of 18-35 years old, $363(89.9 \%)$ were married and $341(84.2 \%)$ of them were from urban. One-third 122 (30.2\%) of mothers attended secondary education, and $106(26.2 \%)$ were government employees. Among all respondents $343(84.9 \%)$ of them had ante-natal care (ANC) follow-up, 378 (93.6\%) of them gave birth at health institution and 245 (60.6\%) had PNC follow-ups (Table 1).

\section{Knowledge on neonatal danger signs}

Mothers' knowledge about NDSs was assessed; those who had mentioned more than or equal 3 general danger signs were considered as having good knowledge about NDSs. Only one-fifth $82(20.3 \%)$ of postpartum mothers possess good-knowledge about NDSs (95\% CI 16.1-24.8).

Among all mothers, $282(70.0 \%)$ of them were able to mention at least one NDSs and 121 (30.0\%) don't know any. Fever 174 (43.1\%), poor feeding/sucking 150 (37.1\%) and difficulty of breathing $86(21.3 \%)$ were the commonly mentioned danger-signs. Major source of information for mothers were health-workers during delivery 155 (38.4\%), from mass-media 34 (8.4\%), health-worker during PNC 11 (2.7\%) and 83 (20.3\%) from other health workers. In 43 (10.2\%) of mothers their current baby had developed one of those danger-signs of which 22 (5.4\%) had fever and 16 (4.0\%) of them had poor feeding/sucking. Among those whom their baby developed dangersign $26(60.5 \%)$ of them sought medical care from health facility immediately, 9 (20.9\%) awaited and improved by itself and 8 (18.6.9\%) sought medical care for their baby after it gets worsened (Fig. 1).

\section{Factors associated with post-partum mothers' knowledge on NDSs}

On bivariate analysis mother's education, occupation, average monthly income, source of information about NDSs, residence, ANC attendance, number of ANC visits, place of delivery, developed maternal danger sign, PNC follow-ups, new-born developed danger sign, counseled on newborn care before discharge after delivery and those who received education on danger sign were found to be associated with knowledge on NDSs at $\mathrm{p}$-value of $<0.2$.
Table 1 Socio-demographic characteristics and maternal health care services utilizations among postpartum mothers attending immunization at health facilities in Ambo town, Central Ethiopia, $2018(\mathrm{~N}=404)$

\begin{tabular}{|c|c|c|}
\hline Variables & Frequency & Percentage (\%) \\
\hline \multicolumn{3}{|l|}{ Mothers age in year } \\
\hline $18-35$ & 373 & 92.3 \\
\hline $36-45$ & 31 & 7.7 \\
\hline \multicolumn{3}{|l|}{ Mothers residence } \\
\hline Urban & 341 & 84.4 \\
\hline Rural & 63 & 15.5 \\
\hline \multicolumn{3}{|l|}{ Mothers marital status } \\
\hline Married & 363 & 89.9 \\
\hline Single & 15 & 3.7 \\
\hline Divorced/widowed & 26 & 6.4 \\
\hline \multicolumn{3}{|l|}{ Mothers occupation } \\
\hline Governmental employed & 106 & 26.2 \\
\hline Self employed & 77 & 19.1 \\
\hline House wife & 87 & 21.5 \\
\hline Farmer & 38 & 9.4 \\
\hline Merchant & 49 & 12.1 \\
\hline Student & 32 & 7.9 \\
\hline Other occupation & 15 & 3.7 \\
\hline \multicolumn{3}{|l|}{ Mothers educational status } \\
\hline Unable to read and write & 44 & 10.9 \\
\hline Able to read and write & 46 & 11.4 \\
\hline Primary school & 82 & 20.3 \\
\hline Secondary school & 122 & 30.2 \\
\hline Diploma and above & 110 & 27.2 \\
\hline \multicolumn{3}{|l|}{ Mothers religion } \\
\hline Orthodox & 165 & 40.8 \\
\hline Muslim & 28 & 6.9 \\
\hline Protestant & 188 & 46.5 \\
\hline Other religion & 23 & 5.7 \\
\hline \multicolumn{3}{|l|}{ Mother ethnicity } \\
\hline Oromo & 344 & 85.1 \\
\hline Amhara & 55 & 13.6 \\
\hline Other ethnicity & 5 & 1.2 \\
\hline \multicolumn{3}{|c|}{ Average family monthly income with Ethiopian birr } \\
\hline$<1000$ & 112 & 27.7 \\
\hline $1001-2000$ & 115 & 28.5 \\
\hline $2001-3674$ & 76 & 18.8 \\
\hline$>3675$ & 101 & 25.0 \\
\hline \multicolumn{3}{|l|}{ Age of current baby in day } \\
\hline $0-28$ & 88 & 21.8 \\
\hline$>29$ & 316 & 78.2 \\
\hline \multicolumn{3}{|l|}{ Parity } \\
\hline 1 & 123 & 30.4 \\
\hline $2-4$ & 263 & 65.1 \\
\hline$\geq 5$ & 18 & 4.5 \\
\hline \multicolumn{3}{|c|}{ Attended ANC during latest pregnancy } \\
\hline Yes & 343 & 84.9 \\
\hline No & 61 & 15.1 \\
\hline
\end{tabular}


Table 1 (continued)

\begin{tabular}{lcc}
\hline Variables & Frequency & Percentage (\%) \\
\hline Number of ANC visits & & \\
No ANC follow up & 61 & 15.1 \\
1st to 3rd visit & 156 & 38.6 \\
4th visit & 187 & 46.3 \\
Place of delivery & & \\
Home & 26 & 6.4 \\
Hospital & 218 & 54.0 \\
Health center & 160 & 39.6 \\
No & 111 & 27.5 \\
Provided counseling on new born care after delivery before discharge \\
Yes & 137 & 33.9 \\
No & 267 & 66.1 \\
Received PNC services & & \\
Yes & 245 & 60.6 \\
No & 159 & 39.4 \\
Number of PNC visits & & \\
No & 159 & 39.4 \\
Once & 126 & 31.2 \\
Twice & 95 & 23.5 \\
Three & 24 & 5.9 \\
Health education received during PNC follow up on & \\
Immunization & 181 & 44.8 \\
Family planning & 161 & 39.9 \\
Breast feeding and care & 79 & 19.6 \\
Neonatal danger sign & 31 & 2.0 \\
Care to ill neonates & 8 & \\
\hline & & \\
& &
\end{tabular}

On multivariable logistic regression analysis mother's educational status, those who received PNC services, current newborn developed danger sign and those who were counseled on newborn care before discharge after delivery were factors that are found to be significantly associated with having good knowledge on NDSs.

In this study those mothers who have diploma/more education were five times more-likely to have good knowledge than those who are unable to read and write $(\mathrm{AOR}=5.25,95 \% \mathrm{CI} 1.48-18.59)$ and those mothers whom their current baby developed danger signs were three times more-likely to have good knowledge than those who weren't (AOR $=3.1895 \%$ CI 1.06-9.52).

Current study also revealed that those mothers who had PNC follow-up were two times more-likely to have good knowledge than those who weren't $(\mathrm{AOR}=2.29$, CI 1.24-4.24) and mothers who had received counseling on newborn-care after delivery were almost two-times more-likely to have good knowledge than those who weren't $(\mathrm{AOR}=1.78, \mathrm{CI} 1.04-3.04)$ (Table 2).

\section{Discussion}

This study assessed the level of knowledge on NDSs and associated factors among postpartum-mothers at public health institutions in Ambo town. It was found that only $20.3 \%$ of postpartum-mothers were having good knowledge about NDSs (95\% CI 16.1-24.8). Which is nearly inline with study conducted in Kenya (15.5\%), Nepal (26.30\%) and Gondar town (18.2\%) mothers had

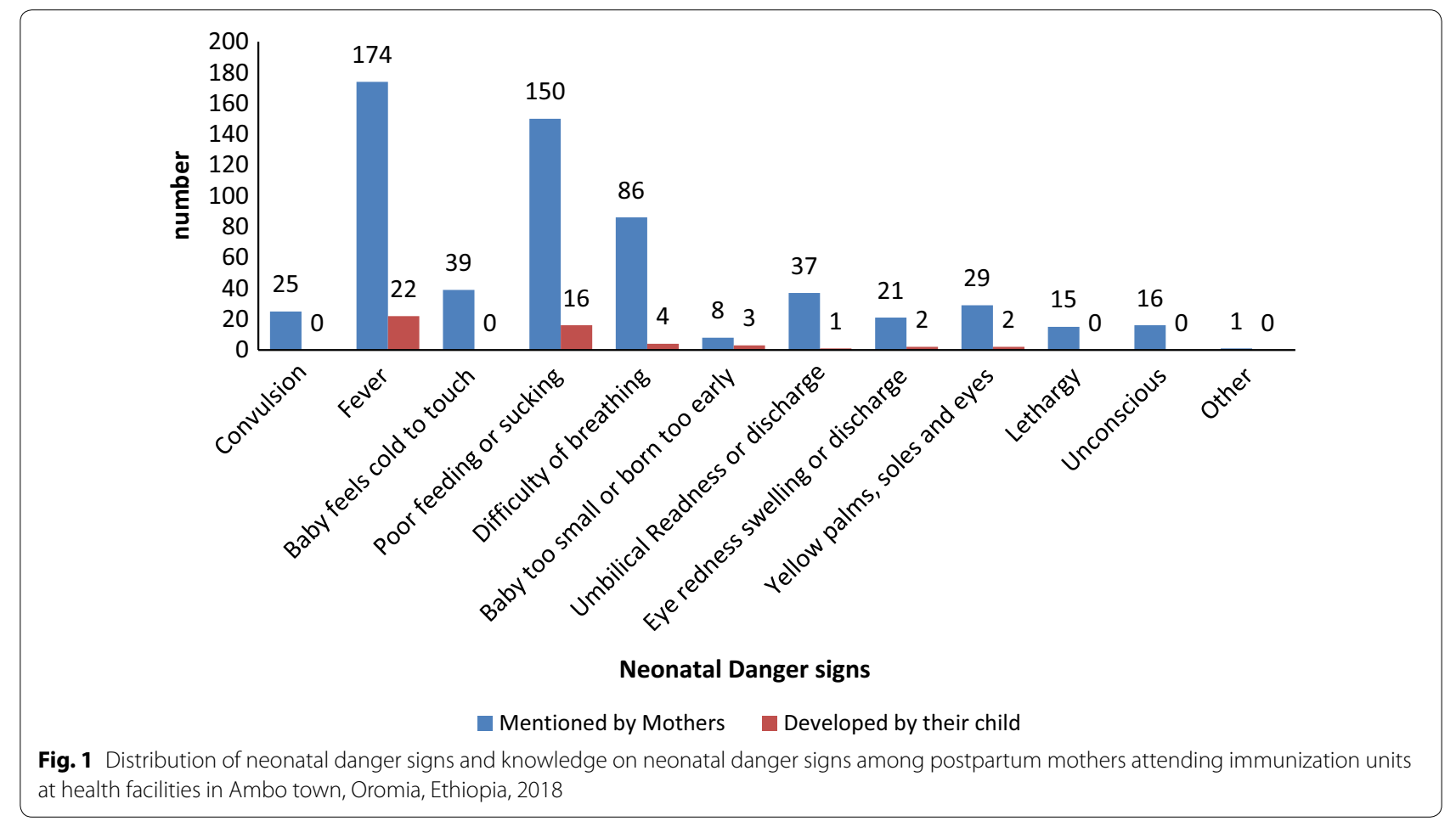


Table 2 Factors associated with good knowledge about neonatal danger signs among postpartum mother's attending immunization units in Ambo town, Oromia region, Ethiopia, 2018 ( $N=404)$

\begin{tabular}{|c|c|c|c|c|c|}
\hline \multirow[t]{2}{*}{ Variables } & \multicolumn{2}{|c|}{$\begin{array}{l}\text { Knowledge on neonatal danger } \\
\text { signs }\end{array}$} & \multirow[t]{2}{*}{ COR with $95 \% \mathrm{Cl}$} & \multirow[t]{2}{*}{ AOR with $95 \% \mathrm{Cl}$} & \multirow[t]{2}{*}{ p value } \\
\hline & Good & Poor & & & \\
\hline \multicolumn{6}{|l|}{ Mothers education } \\
\hline Unable to read and write & 3 & 41 & 1 & 1 & 0.015 \\
\hline Able to read and write & 6 & 40 & $2.05(0.48,8.76)$ & $1.91(0.43,8.39)$ & 0.388 \\
\hline Primary school & 16 & 66 & $3.31(0.9,12.07)$ & $2.76(0.73,10.3)$ & 0.131 \\
\hline Secondary school & 21 & 101 & $2.84(0.8,10.04)$ & $2.34(0.64,8.46)$ & 0.195 \\
\hline Diploma and above & 36 & 74 & $6.64(1.92,22.9)$ & $5.25(1.4,18.5)$ & $0.010^{*}$ \\
\hline \multicolumn{6}{|l|}{ Mothers residence } \\
\hline Urban & 77 & 264 & $3.38(1.31,8.73)$ & & \\
\hline Rural & 5 & 58 & 1 & & \\
\hline \multicolumn{6}{|c|}{ Attended ANC on last pregnancy } \\
\hline Yes & 78 & 265 & $4.19(1.47,11.9)$ & & \\
\hline No & 4 & 57 & 1 & & \\
\hline \multicolumn{6}{|l|}{ Number of ANC visits attend } \\
\hline No follow-up & 4 & 57 & 1 & & \\
\hline $1-2$ times & 10 & 39 & $3.65(1.06,12.4)$ & & \\
\hline 3 times & 29 & 78 & $5.29(1.76,15.9)$ & & \\
\hline 4 times & 39 & 148 & $3.75(1.28,10.9)$ & & \\
\hline \multicolumn{6}{|l|}{ Place of delivery } \\
\hline Home delivery & 2 & 24 & 1 & & \\
\hline Health Institution & 80 & 298 & $3.22(0.74,13.9)$ & & \\
\hline \multicolumn{6}{|l|}{ Received PNC follow up } \\
\hline Yes & 65 & 180 & $3.01(1.69,5.37)$ & $2.29(1.24,4.24)$ & $0.008^{*}$ \\
\hline No & 17 & 142 & 1 & 1 & \\
\hline \multicolumn{6}{|c|}{ New born developed danger sign } \\
\hline Yes & 4 & 39 & $2.68(0.93,7.74)$ & $3.18(1.06,9.52)$ & $0.038^{*}$ \\
\hline No & 78 & 283 & & 1 & \\
\hline \multicolumn{6}{|c|}{ Counseled on new born care before discharge after delivery } \\
\hline Yes & 39 & 98 & $2.07(1.26,3.39)$ & $1.78(1.04,3.04)$ & $0.035^{*}$ \\
\hline No & 43 & 224 & & 1 & \\
\hline \multicolumn{6}{|c|}{ Received education on danger signs } \\
\hline Yes & 6 & 12 & $2.03(0.74,5.6)$ & & \\
\hline No & 76 & 310 & 1 & & \\
\hline
\end{tabular}

*Statistically significant association at P-value of $\leq 0.05$ with backward stepwise logistic regression

good knowledge on neonatal danger signs [20, 22, 23]. But, the current study finding is lower-than studies done in Mekele (50.6\%), Wolkite town (31.32\%) and Chencha district Ethiopia (50.3\%) of mothers have good knowledge about NDSs $[17,18,21]$. The possible reason for this variation might be due to the differences in health care services delivery in which information on danger-sign was not adequately disseminated to mothers both during antenatal and postnatal care, health care providers mainly focuses on care of mothers and neonates than giving health education on danger-signs in our study area.
Newborns with danger-signs were at higher risk of death those than who weren't. Healthcare-seeking behavior of mothers for their newborn by recognizing those serious illnesses was important to avoid delays in making decision which contributes for neonatal mortality. In this study only $60.5 \%$ of mothers whom their baby developed danger-sign sought health care from health facility immediately. This finding was higher than study done in four regions of Ethiopia (1/3rd) and Tenta district (41.3\%) women sought medical care for NDSs [27, 28]. The possible reason for this might be due to the variations in time, study setting, study population and cultural variations in 
which studies in four regions of Ethiopia and Tenta district were conducted in 2014 and 2015, were communitybased, majority were from rural and there were cultural reasons of keeping neonates inside home; but in current study majority of them were from urban and it was conducted among those mothers who came for immunizing their babies.

In this study educational status of mothers were found to be significantly associated with their knowledge. Mothers with diploma or more education were five times more-likely to have good knowledge than those who are unable to read and write. This is in-line with studies done at Woldia general hospital, Gondar and Wolkite towns $[18,22,24]$.

Maternal health services utilizations are also associated with higher knowledge of newborn danger signs. Current study revealed that those mothers who had PNC followup were two times more-likely to have good knowledge than those who weren't and mothers who had received counseling on newborn care after delivery were almost two times more-likely to have good knowledge than those who weren't. Incongruent with this study done in Mekele, Woldia hospital, Wolkite and North-west Ethiopia showed that PNC advice on NDSs, information about neonatal danger-signs, PNC attendance, access to television were factors for having good knowledge about NDSs $[17,18,22,24]$.

Mothers whom their current baby had developed danger signs were three times more-likely to have good knowledge than those who aren't. The possible reason for this might be due to those mothers whom their current baby developed danger-signs were more-likely to seek information and care from health workers for their sick baby from where they could get awareness about NDSs.

\section{Conclusion}

The level of postpartum mother's knowledge on NDSs and care-seeking practice for their newborn with danger sign is low in the study area as knowing those general danger signs is important for early detection of serious illness and seeking health care for their child from health facilities. This study identified that those who had diploma/higher education, current baby developed danger-signs, PNC follow-ups and received counseling on newborn care after delivery before discharge were factors significantly associated with having good knowledge about NDSs.

Therefore provision of health education and counseling/advices for mothers after delivery and during PNC follows-ups on NDSs to improve their knowledge and health care-seeking behavior were the key areas of intervention.

\section{Limitations}

Though the study tried to address knowledge and careseeking practice of postpartum mothers who brought their children for 1st immunization it isn't free of recall bias.

\section{Abbreviations}

ANC: ante natal care; AOR: adjusted odds ratio; NDSs: neonatal danger signs; PNC: post natal care.

\section{Acknowledgements}

We are grateful to Ambo University, College of Medicine and Health Sciences for funding this research and Ambo town health institutions for their support during data collection. We would also like thank Merobi Dereje, Getahun Tamiru, Adamu Irefa and Lense Galmessa for their support during proposal development, data collection and entry in many ways. We also appreciate the cooperation's of all study respondents.

\section{Authors' contributions}

$G A B$, conceptualized the study, designed the study instrument and conducted the data analysis and wrote the first draft and subsequent drafts of the manuscript as principal investigator. DBF, BEM, GAD and KBD participated in designing the study tool, conducted data analysis and revised subsequent drafts. All authors read and approved the final manuscript.

\section{Funding \\ No funding was received.}

\section{Availability of data and materials}

Datasets used in current study are available from the corresponding author up-on request.

\section{Ethics approval and consent to participate}

Ethical clearance was obtained from ethics review committee of Ambo University, College of Medicine and Health Sciences. Formal letter of cooperation was written from College of Medicine and Health Sciences to all public health facilities and letter of permission were also obtained from each health facilities administration. Since the data for this study was collected through an interview which has minimal risk of harm or discomfort on participants, we have used verbal informed consent from each respondents after explaining the purpose and objectives of the study; which was also approved by ethics review committee.

\section{Consent to publish}

Not applicable.

\section{Competing interests}

The authors declare that they have no competing interests.

\section{Author details}

${ }^{1}$ Department of Midwifery, College of Medicine and Health Sciences, Ambo University, Ambo, Ethiopia. ${ }^{2}$ Department of Public Health, College of Medicine and Health Sciences, Ambo University, Ambo, Ethiopia.

Received: 30 June 2019 Accepted: 21 August 2019

Published online: 28 August 2019

\section{References}

1. Hug L, Sharrow D, You D. Levels \& trends in child mortality: report 2017. Estimates developed by the UN Inter-agency Group for Child Mortality Estimation. 2017.

2. Kananura RM, Tetui M, Mutebi A, Bua JN, Waiswa P, Kiwanuka SN, et al. The neonatal mortality and its determinants in rural communities of Eastern Uganda. Reprod Health. 2016;13(1):13.

3. MCEE W. MCEE-WHO methods and data sources for child causes of death 2000-2015. Geneva: World Health Organization; 2016. 
4. Baqui AH, Mitra DK, Begum N, Hurt L, Soremekun S, Edmond K, et al. Neonatal mortality within 24 hours of birth in six low-and lower-middle-income countries. Bull World Health Organ. 2016;94(10):752.

5. Organization WH. Newborns: reducing mortality: key fact sheets. Geneva: World Health Organization; 2018.

6. Nega Assefa FT, Yihunie Lakew, Gashaw Andarge, Befikadu Tariku, Alemseged Aregay, Wubegzier Mekonnen, Tariku Dejene, Muluemebet Abera, Etsehiwot Tilahun. Trends and causes of neonatal death in Ethiopian, 2010-14: health and demographic surveillance system Ethiopian Universities Research centers' Network. Policy Brief. 2016.

7. UNICEF. Maternal and newborn health disparities: Ethiopia: key facts. In: UNICEF, editor. Unicef for every child. 2016.

8. Mengesha HG, Sahle BW. Cause of neonatal deaths in Northern Ethiopia: a prospective cohort study. BMC Public Health. 2017;17(1):62.

9. ICF CSACEa. Ethiopia demographic and health survey 2016: key indicators report. Addis Ababa: CSA and ICF; 2016. p. 2016.

10. Berhan Y, Berhan A. Perinatal mortality trends in Ethiopia. Ethiopian J Health Sci. 2014;24:29-40.

11. (UNICEF) UNCF. Maternal and newborn health disparities in Ethiopia: key facts United States United Nations Childrens Fund. New York: UNICEF; 2017.

12. Organization WH. MCEE-WHO methods and data sources for child causes of death 2000-2016. Global health estimates technical paper. WHO/ HMM/IER/GHE/20181. Geneva:WHO; 2018.

13. Awasthi S, Verma T, Agarwal M. Danger signs of neonatal illnesses: perceptions of caregivers and health workers in northern India. Bull World Health Organ. 2006;84:819-26.

14. Group YICSS. Clinical signs that predict severe illness in children under age 2 months: a multicentre study. Lancet. 2008;371(9607):135-42.

15. Salih FA, Eltyeb EE. Neonatal mortality contributors using the three delays audit: a study from Albuluk paediatrics teaching hospital in Sudan. Int J Res Med Sci. 2017:5(12):5139-44.

16. Ekwochi U, Ndu IK, Osuorah CD, Amadi OF, Okeke IB, Obuoha E, et al. Knowledge of danger signs in newborns and health seeking practices of mothers and care givers in Enugu state, South-East Nigeria. Ital J Pediatr. 2015;41(1):18.

17. Adem N, Berhe KK, Tesfay Y. Awareness and associated factors towards Neonatal Danger Signs among Mothers Attending Public Health Institutions of Mekelle City, Tigray, Ethiopia, 2015. J Child Adolesc Behav. 2017;05(06):365.

18. Anmut W, Fekecha B, Demeke T. Mother's knowledge and practice about neonatal danger signs and associated factors in Wolkite Town, Gurage Zone, SNNPR, Ethiopia, 2017. J Biomed Sci. 2017;06(05):33.
19. Berhe M, Medhaniye AA, Kahsay G, Birhane E, Abay M. Essential neonatal care utilization and associated factors among mothers in public health facilities of Aksum Town, North Ethiopia, 2016. PLoS ONE. 2017;12(4):e0175902.

20. Kibaru EG, Otara AM. Knowledge of neonatal danger signs among mothers attending well baby clinic in Nakuru Central District, Kenya: cross sectional descriptive study. BMC Res Notes. 2016;9(1):481.

21. Mersha A. Mother's level of knowledge on neonatal danger signs and its predictors in Chencha District, Southern Ethiopia. Am J Nurs Sci. 2017;6(5):426.

22. Nigatu SG, Worku AG, Dadi AF. Level of mother's knowledge about neonatal danger signs and associated factors in North West of Ethiopia: a community based study. BMC Res Notes. 2015;8(1):309.

23. Sushila Devi Bhandari SSP. Knowledge and practice of postnatal mothers on newborn care at hospital setting. ARC J Nurs Healthc. 2016;2(1):25-30.

24. Jemberia MM, Berhe ET, Mirkena HB, Gishen DM, Tegegne AE, Reta MA. Low level of knowledge about neonatal danger signs and its associated factors among postnatal mothers attending at Woldia general hospital, Ethiopia. Matern Health Neonatol Perinatol. 2018;4(1):5.

25. Okawa S, Ansah EK, Nanishi K, Enuameh Y, Shibanuma A, Kikuchi K, et al. High incidence of neonatal danger signs and its implications for postnatal care in Ghana: a cross-sectional study. PLoS ONE. 2015;10(6):e0130712.

26. Mersha A, Assefa N, Teji K, Bante A, Shibiru S. Mother's level of knowledge on neonatal danger signs and its predictors in Chencha District, Southern Ethiopia. Am J Nurs. 2017;6(5):426-32.

27. Bekele A, Tensou B, Molla Y, Johnson J, Snetro G, Kabue A, et al. Assessing knowledge practice and coverage of newborn care services in Ethiopia: baseline household survey informs programming for community-based care. 2017.

28. Molla G, Gonie A, Belachew T, Admasu B. Health care seeking behaviour on neonatal danger signs among mothers in Tenta District, Northeast Ethiopia: community based cross-sectional study. Int J Nurs Midwifery. 2017;9(7):85-93.

\section{Publisher's Note}

Springer Nature remains neutral with regard to jurisdictional claims in published maps and institutional affiliations.
Ready to submit your research? Choose BMC and benefit from:

- fast, convenient online submission

- thorough peer review by experienced researchers in your field

- rapid publication on acceptance

- support for research data, including large and complex data types

- gold Open Access which fosters wider collaboration and increased citations

- maximum visibility for your research: over $100 \mathrm{M}$ website views per year

At BMC, research is always in progress.

Learn more biomedcentral.com/submissions 